\title{
The Moderating Effect of Occupation on the Relationship between Anger and Mental Health among Extroverted and Introverted Women
}

\author{
Maryam Safara $^{1 *}$, Somayeh Keshavarz ${ }^{2}$ \\ ${ }^{1}$ Alzahra University, Women Research Center, Tehran, Iran \\ ${ }^{2}$ Islamic Azad University, Karaj, Alborz, Iran \\ Email: Safara maryam@yahoo.com, ${ }^{*}$ m.safara@alzahra.ac.ir
}

Received 19 July 2015; accepted 26 September 2015; published 30 September 2015

Copyright (C) 2015 by Author and Scientific Research Publishing Inc.

This work is licensed under the Creative Commons Attribution International License (CC BY). http://creativecommons.org/licenses/by/4.0/

\section{(c) (i) Open Access}

\section{Abstract}

This study intends to investigate the moderating effect of occupation on the associations between anger and mental health between introverted and extroverted women. Available sampling was used for collecting the data. Sample consisted of 384 women including 192 employed women and 192 housewives women (Mean age $=31.63$ ). A self-administered questionnaire was prepared for the participants. Instruments in the present study included general health questionnaire (GHQ- 28), aggression as well as the scale that assessed respondents' introversion and extroversion. Results showed that aggression negatively related to mental health. In contrast, there was positive relationship between control wrath and mental health. Meaningly, women with high level of conciliation tended to possess high mental health. Furthermore, occupation didn't play the moderating role in the associations between anger and mental health between introverted and extroverted women.

\section{Keywords}

Aggression, Occupation, Introversion, Extroversion

\section{Introduction}

Diagnosing and treating aggressive people has been an increasing concern to clinicians, health institutes, and

\footnotetext{
${ }^{*}$ Corresponding author.
}

How to cite this paper: Safara, M. and Keshavarz, S. (2015) The Moderating Effect of Occupation on the Relationship between Anger and Mental Health among Extroverted and Introverted Women. Open Journal of Medical Psychology, 4 111-115. http://dx.doi.org/10.4236/ojmp.2015.44011 
humanity as a whole. Some theorists believe that aggression is a type of antisocial behavior in which one deliberately aims to harm person, or objects [1]. In other words, anger is a maladaptive effort at stealing with a stressful environment, resulting in more personal discomfort and greater conflict [2] [3]. There are three kinds of aggression in terms of the form or type of aggressive behavior such as physical aggression, verbal aggression, and relational aggression. Physical aggression is aggressive behavior characterized by punching, hitting, slapping, kicking, scratching, and similar actions intended to do physical harm. The other observed types of aggressionverbal and relational aggression-do not involve physical harm and are more common as children acquire enhanced verbal and social sophistication [4]. Verbal aggression involves face-to-face encounters in which one harms another person or persons through malicious teasing, name calling, insults, threats, or other similar behavior [5]. Relational aggression refers to manipulate behavior intended to harm social relationships or damage social status [5].

However, recent researches have concentrated on anger as an adaptive mechanism for coping with obstructed aims and perceived threats [2] [6]. Healthy anger has been differentiated from unhealthy anger in terms of how effectively the emotion provides the basic needs of the individual [7]. For instance, the anger response was healthy if a person made a quirky remark in an angry response to a coworker's rude comment since he positively resolved the situation. In contrast, if the person punched the rude coworker, which led to endanger employment, the anger response was unhealthy.

People with high level of angry are often unable to suitably manage stress and therefore become frustrated, which certainly leads to increased anger [2] [7] [8]. They may become angry in conditions where it is not a useful emotion and may have difficulty in resolving the anger successfully. Therefore, anger can be powerful forces to prepare and protect individuals from harm. The failure to experience this emotion in the face of threat might result in decreased coping resources. However, this emotion can become problematic if they are evoked too frequently or too intensely, or if they remain for a long period of time.

In addition, anger is significant predictor of poor health and can cause impairment in individual's satisfaction, health, and interpersonal relationships [9]. Various studies also show that there is a relationship between tendency to experience anger and different factors such as low self-esteem, unemployment, educational problems, interpersonal difficulties and mental health [10].

Mental health is defined as a level of psychological well-being, or an absence of a mental disorder. The person with mental illness encounters with several problems in daily life, such as at work or in relationships [11] [12]. These problems often cause the feelings of sadness, stress or nerves. Many of these problems may lead to personal and social difficulties or reactions to life events such as physical illness or unemployment [13]. Previous research demonstrated that nearly half of the world's population was influenced by mental illness with an impact on their relationships, self-esteem and ability to function in everyday life [14].

Therefore, previous studies have established valuable knowledge about the relationships between aggression and mental health [15] [16]. Numerous studies show that employment is useful for general mental health [17]. Conversely, aggression has a negative influence on employment and occupational behavior [18]. Therefore, much is to be understood on the moderating effect of occupation on these relationships. Furthermore, traditional roles of women have changed, to some extent, in developing countries. Therefore, they spend most of their time doing outdoor activities instead of doing just houseworks [19]. Because of the important role of women in affairs of family, job may consider as a stressor that has adverse effects on them and other family members and would decrease their quality of life [20]. Several researches indicate that there is constantly different role conflict between women's indoor and outdoor activities and facing these problems is regarded as a risk factor for their mental health. Therefore, the main goal of the present study is to examine the moderating roles of occupation on the relationships between aggression and mental health. In addition, it is essential to further examine the specific conditions under which these moderating effects exist.

\section{Method}

This quantitative study employed a cross-sectional survey and correlational research design. In the cross-sectional survey research design, all the information is gathered at a single time of the respondent's life. The correlational method was used to find out the pattern of relationship between variables. Correlational research investigates the extent to which variables are related and the direction of the relations. There is no manipulation of the variables. Correlational design relates two or more variable measures from the same group of subjects [21]. 


\subsection{Participants}

Our population comprised of employed women and housewives who are living in Tehran and Karaj during the Academic year of 1392-1393. The sample of this study consisted of 384 women with the average age of 31.63. There were equal proportions of employed and housewife women. Available sampling was also used for this study.

\subsection{Instrument}

General Health Questionnaire (GHQ-28): This questionnaire was developed by Goldberg in 1972 and consisted of four subscales. It is one of the most popular and reliable scales for screening the psychological disorder [22]. The psychometric properties of GHQ-28 were determined according to the Iranian psychiatric population. Furthermore, the Cronbach's alpha and concurrent validity were obtained based on correlation with checklist of psychological problems [23]. It includes 28 items and each item rated on a 4-point Likert-type scale from 1(Not at all) to 4 (Much more than usual).

Misheal Gocklen Introversion and Extroversion Questionnaire: It includes 50 questions and for each questions two responses are considered. Responses are grouped on the basis of scores. Final responses are made on a 7-point Likert scale ranging from 1 (scores less than 5 which labeled as introversion) to 7 (scores more than 45 which labeled as extroversion).

Aggression Questionnaire: This Questionnaire was designed by the researcher. It consisted of 61 questions and responses to the CWQ are made on a 4-point Likert scale, ranging from $1=$ never to $4=$ almost always. By summing the responses to all sixty one items, the CWQ yields a total composite score. Finally, the total score standardized. Scores less than zero refers to control wrath and more than zero refers to aggression. In this questionnaire, 80 statements were chosen by the researchers. Content validity performed for this questionnaire, this procedure was carried out by eight academic people in the university to select the suitable statements. Finally 61 statements have been selected and pilot study was conducted on participants and provided invaluable information regarding the instrument. Each item in the questionnaire was re-inspected before the actual study was conducted. Additionally, In order to establish the psychometric quality of the scales, coefficient alpha values were obtained. The result of the pilot study indicated acceptable alpha values (0.77).

\section{Results}

The means, standard deviations and alpha coefficients for each variable were calculated. Additionally zero-order correlations were performed to assess possible inter correlations among variables. Hierarchical regression analyses were conducted to examine the interactive effects of aggression and the moderator variable (occupation) in predicting women's mental health. To provide more information regarding the significant interaction effects, post-hoc probing techniques were performed using conditional moderator variables [24] [25].

\subsection{Descriptive Analyses and Correlations}

Table 1 indicates alpha coefficients, means, and standard deviations, for each subscale. For all the scales the internal consistency (Cronbach's alpha) method was utilized.

Additionally, Pearson Product-Moment correlation was used and following the scientific research tradition, all calculations were conducted at alpha 0.05 (2-tailed). As presented in Table 2, the results from the correlation analyses identified patterns of intercorrelations among variables. Specifically, conciliation had significantly positive relationships with mental health among women. It showed that women with low level of mental health tended to indicate high level of aggression. In contrast, it showed that women tended to possess high mental health when they showed high level of control wrath.

\subsection{Regression Analyses}

Hierarchical regression analyses were conducted to examine the moderating role of occupation. As it has been shown in Table 3, aggression variable was entered in Step 1 and occupation as a moderator variable entered in step 2. In addition, hierarchical multiple regression analysis provides the statistical testing of a moderator effects by including their product or interaction term at a later step in the regression equation [26] [27]. The change in $\mathrm{R}^{2}$ and standardized $\mathrm{b}$ weights were inspected. The interaction effect was not significant. 


Table 1. Descriptive indicators.
\begin{tabular}{cccc}
\hline Variables & Alpha coefficient & Mean & Standard deviation \\
\hline Aggression & 0.678 & 81.2 & 1.93 \\
Mental health & 0.898 & 62.4 & 1.15 \\
Introversion-Extroversion & 0.596 & 27.3 & 5.85 \\
\hline
\end{tabular}

Table 2. Correlation between variables.

\begin{tabular}{ccc}
\hline & Variables & Mental health \\
\hline & Agression & $-0.26^{* *}$ \\
\hline${ }^{* *} \mathrm{p} \leq 0.01$ & &
\end{tabular}

Table 3. The moderating effect of occupation.

\begin{tabular}{rccccc}
\hline Variables & F (P) & $\mathbf{R}^{2}$ & B & b \\
\hline Step 1 anger & 0.07 & 0.00 & -0.03 & -0.02 \\
Step 2 occupation & 2.28 & $0.03^{*}$ & $-6.64^{*}$ & $-0.16^{*}$ \\
Step 3 anger occupation & 1.51 & 0.03 & -0.01 & -0.02 \\
${ }^{*} \mathrm{p} \leq 0.05$ & & & &
\end{tabular}

\section{Conclusion}

The purpose of the present study was to examine the moderating role of occupation on the association between anger and mental health between extroverted and introverted women. The first hypothesis regarding aggression and their associations with women's mental health was supported that aggression was related to low level of mental health. This is consistent with the findings of previous researches [28] [29] which have shown that aggression is associated with mental illness. The second hypothesis regarding the moderating effect of occupation on the relationship between aggression and mental health was not supported. The present study makes several contributions to the literature by providing data on an important and understudied population of Iranian women and by bringing together a number of different constructs. In addition, the limitation of this study is related to the research designs. The design of the present study does not allow for the identification of causality. The findings are correlational and may be suggestive, but it is only through the use of longitudinal designs that causality could be investigated.

\section{References}

[1] Dodge, K.A. (1991) The Structure and Function of Reactive and Proactive Aggression. In: Pepler, D. and Rubin, K., Eds., The Development and Treatment of Childhood Aggression, Lawrence Erlbaum Associates, Inc., Hillsdale, 201218.

[2] Cox, D.L., Stabb, S.D. and Bruckner, K.H. (1999) Women’s Anger: Clinical and Developmental Perspectives. BraunBrumfield, Ann Arbor.

[3] Novaco, R.W. (1975) Anger Control: The Development and Evaluation of an Experimental Treatment. Lexington Books, Lexington.

[4] Cairns, R., Cairns, B., Neckerman, H., Ferguson, L. and Gariepy, J. (1989) Growth and Aggression: I. Childhood to Early Adolescence. Developmental Psychology, 25, 320-330. http://dx.doi.org/10.1037/0012-1649.25.2.320

[5] Pepler, D. and Craig, W. (2005) Aggressive Girls on Troubled Trajectories: A Developmental Perspective. In: Pepler, D., Madsen, K., Levene, K. and Webster, C., Eds., The Development and Treatment of Girlhood Aggression, Erlbaum, Hillsdale, 3-28.

[6] Stein, N.L. and Levine, L.J. (1989) The Causal Organization of Emotional Knowledge: A Developmental Study. Cognition and Emotion, 3, 343-378. http://dx.doi.org/10.1080/02699938908412712

[7] Grieger, R.M. (1986) Anger Problems. In: Ellis, A. and Grieger, R., Eds., Handbook of Rational-Emotive Therapy, Vol. 2, Springer Publishing, New York, 121-140. 
[8] Edmondson, C.B. and Conger, J.C (1996) A Review of Treatment Efficacy for Individuals with Anger Problems: Conceptual, Assessment, and Methodological Issues. Clinical Psychology Review, 16, 251-275. http://dx.doi.org/10.1016/S0272-7358(96)90003-3

[9] Fava, M., Anderson, K. and Rosenbaum, J.F. (1990) “Anger Attacks”: Possible Variants of Panic and Major Depressive Disorders. American Journal of Psychiatry, 147, 867-870.

[10] Dahlen, E.R. and Martin, R.C. (2005) The Experience, Expression, and Control of Anger in Perceived Social Support. Personality and Individual Differences, 39, 391-401. http://dx.doi.org/10.1016/j.paid.2005.01.019

[11] Salgado, M.F., et al. (2012) Family History of Serious Mental Illness in Bipolar I and Bipolar II Patients of the Mayo Bipolar Biobank. Biological Psychiatry, 71, $153 \mathrm{~S}$.

[12] Chamberlain, A.M., Vickers, K.S., Colligan, R.C., Weston, S.A., Rummans, T.A. and Roger, V.L. (2011) Associations of Preexisting Depression and Anxiety with Hospitalization in Patients with Cardiovascular Disease. Mayo Clinic Proceedings, 86, 1056-1062. http://dx.doi.org/10.4065/mcp.2011.0148

[13] Bower, P., Knowles, S., Coventry, P.A. and Rowland, N. (2011) Counselling for Mental Health and Psychosocial Problems in Primary Care. The Cochrane Database of Systematic Reviews, No. 9, Article ID: CD001025.

[14] Storrie, K., Ahern, K. and Tuckett, A. (2010) A Systematic Review: Students with Mental Health Problems-A Growing Problem. International Journal of Nursing Practice, 16, 1-6. http://dx.doi.org/10.1111/j.1440-172X.2009.01813.x

[15] Hoeltje, C.O., Zubrick, S.R., Silburn, S.R. and Garton, A.F. (1996) Generalized Self-Efficacy: Family and Adjustment Correlates. Journal of Clinical Child Psychology, 24, 446-453. http://dx.doi.org/10.1207/s15374424jccp2504 9

[16] Juang, L.P. and Silbereisen, R.K. (1999) Supportive Parenting and Adolescent Adjustment across Time in Former East and West Germany. Journal of Adolescence, 22, 719-736. http://dx.doi.org/10.1006/jado.1999.0267

[17] van der Noordt, M., Ijzelenberg, H., Droomers, M. and Proper, K.I. (2014) Health Effects of Employment: A Systematic Review of Prospective Studies. Occupational and Environmental Medicine, 71, 730-736. http://dx.doi.org/10.1136/oemed-2013-101891

[18] Brook, J.S. and Newcomb, M.D. (1995) Childhood Aggression and Unconventionality: Impact on Later Academic Achievement, Drug Use, and Work Force Involvement. The Journal of Genetic Psychology, 156, 393-410. http://dx.doi.org/10.1080/00221325.1995.9914832

[19] Maghsoudi, S. and Bostan, Z. (2004) Study of the Problems Caused by Concurrency of Domestic and Social Roles of Employed Women in Kerman City. Study of Women Magazine, 5, 129-150. (In Persian)

[20] Souri, H. and Saadabad, A.R. (2004) Occupational Stresses in Women. Hakim Magazine, 6, 65-72. (In Persian)

[21] Salkind, N.J. (2006) Exploring Research. 6th Edition, Prince-Hall, Upper Saddle River.

[22] Molina, J.D., Andrade-Rosa, C., Gonzalez-Parra, S., Blasco-Fontecilla, H., Real, M.A. and Pintor, C. (2006) The Factor Structure of the General Health Questionnaire (GHQ): A Scaled Version for General Practice in Spain. European Psychiatry, 21, 478-486. http://dx.doi.org/10.1016/j.eurpsy.2006.03.002

[23] Molavi, H. (2002) Validation, Factor Structure, and Reliability of the Farsi Version of General Health Questionnaire28 on Iranian Students. Pakistan Journal of Psychological Research, 17, 87-98.

[24] Aiken, L.S. and West, S.G. (1991) Multiple Regression: Testing and Interpreting Interactions. Sage, Newbury Park.

[25] Holmbeck, G.N. (2002) Post-Hoc Probing of Significant Moderational and Mediational Effects in Studies of Pediatric Populations. Journal of Pediatric Psychology, 27, 87-96. http://dx.doi.org/10.1093/jpepsy/27.1.87

[26] Baron, R.M. and Kenny, D.A. (1986) The Moderator-Mediator Variable Distinction in Social Psychological Research: Conceptual, Strategic and Statistical Consideration. Journal of Personality and Social Psychology, 51, 1173-1182. http://dx.doi.org/10.1037/0022-3514.51.6.1173

[27] Cohen, J. and Cohen, P. (1983) Applied Multiple Regression/Correlational Analysis for the Behavioral Sciences. Erlbaum Associates, Hillsdale.

[28] Pimple, P., Shah, A., Rooks, C., Bremner, D., Nye, J., Ibeanu, I., et al. (2015) Association between Anger and Mental Stress-Induced Myocardial Ischemia. American Heart Journal, 169, 115-121. http://dx.doi.org/10.1016/j.ahj.2014.07.031

[29] Sousa, C.A., Susan, K. and El-Zuhairi, M. (2014) Dwelling within Political Violence: Palestinian Women’s Narratives of Home, Mental Health, and Resilience. Journal of Health and Place, 30, 205-214. http://dx.doi.org/10.1016/j.healthplace.2014.09.005 